\title{
Políticas públicas de protección social y lucha contra la pobreza en Colombia: logros y desafíos*
}

\section{Public policies on Social Protection and Fight Against Poverty in Colombia: Achievements and Challenges}

Carlo Tassara**

Recibido: $15 / 10 / 2014$

Aprobado: 02/09/2015

Disponible en línea: 30/11/2015

\section{Resumen}

Los propósitos principales de este texto son investigar el estado de implementación de los Programas de Transferencias Condicionadas (PTC) y su aporte a la construcción de sistemas integrales de protección social en América Latina, como también examinar los principales logros y desafíos de la lucha contra la pobreza en Colombia. Con este fin, el artículo inicia con una breve revisión de la situación global de los PTC en América Latina. Le sigue un análisis comparativo de las acciones realizadas en varios países de la región para abordar los desafíos relacionados con las políticas públicas de lucha contra la pobreza. Esto permite esbozar seguidamente un análisis de su manejo en Colombia. Finalmente,

\section{Abstract}

The main purposes of this paper are, on the one hand, to explore the state of implementation of the Conditional Cash Transfer (CCT) Programmes and their contribution to the construction of integrated social protection systems in Latin America, and on the other, to discuss the most important achievements and challenges in fighting against poverty in Colombia. With this target, the article begins with a brief review of the overall situation of the CCT Programmes in Latin America. This is followed by a comparative analysis of actions undertaken in some countries in the region in order to face the main threats related to the public policies to eradicate poverty. It enables to draw an analysis about the

doi:10.11144/Javeriana.papo20-2.ppps

${ }^{*}$ Artículo de reflexión

** Sociólogo y PhD en Teoría e Investigación social. Desde hace más de treinta años trabaja en temas de cooperación para el desarrollo, relaciones euro-latinoamericanas y políticas públicas de inclusión social. Es profesor de Estrategias para la cooperación internacional en la Universidad de Roma Sapienza y dicta clases de posgrado en varias universidades colombianas. Es experto de políticas públicas del Comitato Internazionale per lo Sviluppo dei Popoli (CISP) y consultor en protección social del Programa EUROsociAL de la Unión Europea. Página web: http://uniroma1.academia. edu/CarloTassara 
la última parte del texto plantea algunas hipótesis y propuestas para encarar los problemas anteriormente identificados.

\section{Palabras clave}

América Latina; Colombia; lucha contra la pobreza; políticas públicas; Programas de Transferencias Condicionadas (PTC); protección social management of such challenges in Colombia. Finally, the last part of the paper suggests some hypotheses and proposals in order to address the problems identified above.

\section{Keywords}

Conditional Cash Transfer (CCT) Programmes; Colombia; fight against poverty; Latin America; public policies; social protection

\section{Cómo citar este artículo:}

Tassara, C. (2015). Políticas públicas de protección social y lucha contra la pobreza en Colombia: logros y desafíos. Papel Político, 2O(2), 233-351. http://dx.doi.org/10.11144/ Javeriana.papo20-2.ppps 


\section{Introducción}

Los Programas de Transferencias Condicionadas (PTC) irrumpen en el escenario latinoamericano en la segunda mitad de la década de 1990 y representan una innovación importante por dos razones. La primera es que rompen el esquema tradicional basado en el modelo del seguro social y por ende en la seguridad contributiva. Es así que alientan indirectamente el debate sobre la introducción de los derechos sociales universales vinculados con la ciudadanía. La segunda es que introducen la corresponsabilidad de los beneficiarios con el objetivo de mejorar los niveles de educación, salud y alimentación, y aumentar el capital humano.

En este marco, el presente artículo es una contribución al análisis de las políticas públicas de protección social y lucha contra la pobreza en América Latina y especialmente en Colombia. En particular, sus propósitos son presentar el estado del arte de la reflexión sobre el aporte de los PTC a la inclusión social y la relación entre su implementación y la construcción de los sistemas de protección social en América Latina por un lado, y examinar los principales logros y desafíos de la lucha contra la pobreza en Colombia, por el otro.

La segunda parte del texto plantea sintéticamente los antecedentes y características generales de los PTC, los avances conseguidos en la lucha contra la pobreza, los problemas abiertos en este ámbito y el desafío representado por la construcción de sistemas de protección social en América Latina. La tercera parte propone una revisión comparativa sobre cómo varios países de la región han abordado algunos de los principales desafíos relacionados con las políticas públicas de lucha contra la pobreza, esbozando al mismo tiempo un análisis crítico de su manejo en Colombia. Los desafíos son los siguientes: articulación entre PTC y sistemas de protección social, ruralización de la lucha contra la pobreza, inclusión productiva y generación de ingresos, adultos mayores y sistema pensional, y finalmente, organización y gestión operativa. En la última parte se presentan las principales conclusiones alcanzadas dando énfasis a los cinco temas antes mencionados.

\section{PTC y protección social en América Latina}

Después de la crisis económica y los programas de ajuste estructural de la década de 1980, que en América Latina generan un notable aumento de la pobreza, en la década de 1990 empieza a ganar terreno la conciencia sobre la necesidad de enfrentar el problema de las brechas sociales. El entorno es favorable porque en ese periodo se consolida la institucionalidad democrática y se aprueban la mayoría de las nuevas constituciones ${ }^{1}$.

\footnotetext{
${ }^{1}$ Vale la pena recordar que las mismas abren espacios novedosos para la descentralización del Estado, la consolidación de las autoridades locales, la participación democrática, los derechos de los pueblos indígenas y de otras minorías étnicas, y la igualdad de género.
} 
Asimismo la dirigencia política "apunta a plasmar en algunas acciones concretas la idea de un Estado más presente, con mayor capacidad de intervenir en el desarrollo económico y social” (Repetto, 2010, p. 1). Además, Tassara (2014, p. 11) evidencia que:

[...] organismos como el Banco Mundial, el Banco Interamericano de Desarrollo (BID), el Programa de la Naciones Unidas para el Desarrollo (PNUD), la Comisión Económica para América Latina y el Caribe (CEPAL) y la Unión Europea ${ }^{2}$ han desempeñado un papel proactivo en la promoción de los nuevos paradigmas en la lucha contra la pobreza. Esto ha estimulado mayor atención hacia los enfoques basados en la cohesión social, la ciudadanía y los derechos en la formulación de las políticas sociales.

Lo anterior genera una "preocupación explícita para lograr mejores niveles de distribución de los beneficios del desarrollo económico y disminuir la elevada desigualdad prevalente. Así, las personas pasan de ser consideradas consumidores y beneficiarios en convertirse en ciudadanos titulares de derechos" (Cecchini \& Martínez, 2011, p. 33) y se reconoce que,

En el largo plazo hay un círculo virtuoso entre menores brechas sociales, menores brechas de productividad y un crecimiento más dinámico y sostenido. La evidencia es concluyente, en el sentido de que desarrollo económico e igualdad social tienden a confluir. Baste contrastar la distribución del ingreso y de otros activos en sociedades más pobres y menos pobres. (CEPAL, 2010, p. 43)

En este contexto los PTC son concebidos con el propósito de "transformar y detener la transmisión inter-generacional de la pobreza mediante el desarrollo de las capacidades humanas en las familias más vulnerables" (Cecchini \& Madariaga, 2011, p. 5) creando incentivos para que las familias inviertan en educación, nutrición y salud y por esta vía, asegurar la integración social y el acceso a una mejor calidad de vida.

Los primeros PTC arrancan en Brasil y México (1997), Ecuador y Honduras (1998), Colombia, Costa Rica y Nicaragua (2000). En 2013 operaban en 21 países con una cobertura de 30 millones de familias (unos 127 millones de personas, el 21,5\% de la población total) a un costo cercano al o,4\% del producto interno bruto (PIB) de los países de América Latina y el Caribe (Gráfico 1).

\footnotetext{
${ }^{2}$ Al respecto, tiene especial importancia el trabajo de investigación aplicada e intercambio de buenas prácticas que el "Programa para la cohesión social en América Latina" (Programa EUROsociAL) ha llevado a cabo y sigue realizando en varios países de la región desde 2005 hasta la fecha, con la participación de funcionarios y dirigentes de los gobiernos nacionales de América Latina y de expertos europeos y latinoamericanos.
} 


\section{Gráfico 1. Cobertura e inversión en los PTC en América Latina y el Caribe}
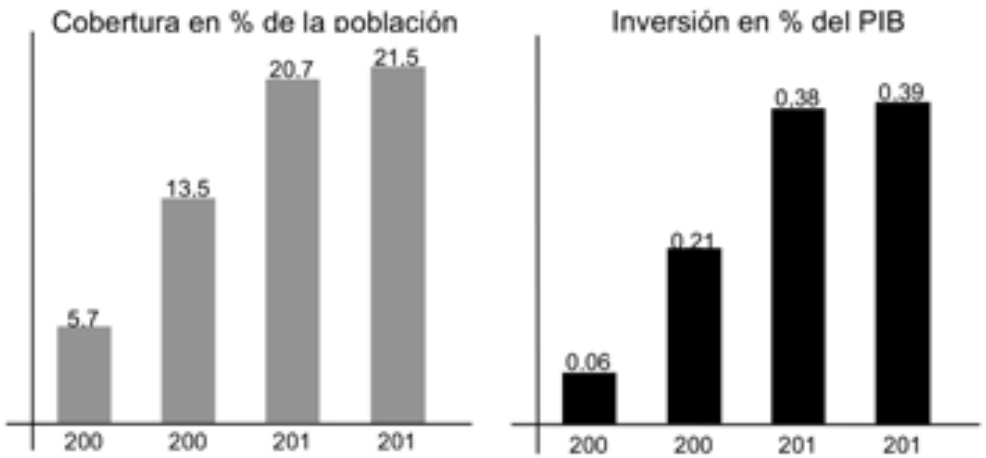

Estimación correspondiente a 21 países de la región en los que operaban los PTC en 2013. Fuente: Base de datos CEPAL (2010) de programas de protección social no contributiva en América Latina y el Caribe.

Los PTC son bastante heterogéneos puesto que reflejan, en cierta medida, la trayectoria histórica y las características políticas, económicas y sociales de cada país de la región. Sin embargo es posible identificar algunos elementos comunes entre ellos en lo referente a la estructura básica, las conductas requeridas, la unidad de intervención y la selección de los destinatarios (Cuadro 1).

\section{Cuadro 1. Elementos comunes de los PTC en América Latina}

La estructura básica consiste en la entrega de recursos a familias en situación de pobreza o indigencia que tengan hijos menores de edad y cumplan con ciertas conductas asociadas al mejoramiento de sus capacidades humanas (definidas 'condicionalidades'). Los recursos pueden ser monetarios (transferencias) o de otro tipo (suplementos alimenticios, mochilas con útiles escolares, etc.).

Las condicionalidades se relacionan con las áreas de educación, salud y nutrición. Entre los compromisos más comunes se encuentran la asistencia de los niños a un porcentaje mínimo de clases, la realización de visitas y otras actividades en los centros de salud, y la participación en charlas y consejerías de orientación en diversos temas.

La unidad de intervención es la familia, con énfasis en niños, niñas y jóvenes en edad escolar. Sin embargo, algunos programas cobijan también a desempleados, personas con discapacidad y adultos mayores. Normalmente las receptoras de las transferencias son las madres, que tienen más propensión a utilizar los recursos para mejorar el bienestar de la familia y de sus hijos. Asimismo, las madres se responsabilizan del cumplimiento de las condicionalidades $y, a$ veces, actúan como promotoras de los programas.

Otro aspecto común es la utilización de criterios para la selección de los destinatarios, generalmente basados en la focalización geográfica y en los métodos de selección de hogares por comprobación indirecta de los medios de vida.

Fuente: Elaboración del autor con base en Cecchini y Madariaga (2011, pp. 13-14). 
Los casos más conocidos son el programa Oportunidades en México y la Bolsa Familia en Brasil, que también se caracterizan por el alto número de beneficiarios, con 6,5 y 13,8 millones de familias respectivamente. Según Tassara (2014, pp. 13-14):

[...] el programa Oportunidades cuenta con el sistema de evaluación más consistente, ha sido respaldado con préstamos de varios miles de millones de dólares por el Banco Mundial y se está replicando en unos quince países de América Latina, Europa y Asia, donde el mismo banco apoya su implementación con recursos financieros y asistencia técnica. Además, Michael Bloomberg, Alcalde de Nueva York, viajó personalmente a México en 2007 para estudiar esta experiencia, que en la actualidad, después de haber sido adaptada a otro contexto, se aplica en Brooklyn con recursos de la Fundación Rockefeller y otros donantes.

Hay quienes critican los PTC por no encarar temas de fondo como la reforma substantiva del mercado laboral, la redistribución equitativa del ingreso y la creación de sistemas de protección social más amplios e incluyentes. Según Midaglia (2012) por ejemplo, estos programas replantean "las viejas ayudas públicas de perfil asistencial, disimuladas con el barniz del nuevo siglo" y propician "la fragmentación del esquema de provisión de bienes sociales y [...] la instalación de programas 'pobres' para grupos 'pobres”'(p. 85) .

$\mathrm{Al}$ mismo tiempo, las evaluaciones y los estudios realizados indican que los PTC generan impactos positivos importantes, como por ejemplo el crecimiento de tasas de matrícula escolar ${ }^{3}$, el mejoramiento de la atención en salud preventiva y el aumento del consumo y de los ingresos familiares (Rangel, 2011, p. 1).

En fin, el crecimiento económico y las políticas sociales redistributivas en los últimos años han permitido grandes avances en la reducción de la pobreza en América Latina, revirtiendo parcialmente las tendencias de las décadas anteriores. Actualmente, además de continuar con este esfuerzo para la superación de la pobreza monetaria y multidimensional, emerge el crucial desafío de enfrentar los problemas de segmentación social y de desigualdad que caracterizan a las sociedades latinoamericanas.

En este contexto, en muchos países se registra una transición con características y cronogramas diferentes, orientadas a incluir los PTC en un marco de políticas públicas que apuntan a la superación del enfoque asistencialista para ayudar a los pobres y a la asunción progresiva de un enfoque universalista que se refleje en la aprobación de leyes nacionales y asegure el cumplimiento de los derechos básicos de la ciudadanía.

\footnotetext{
${ }^{3}$ Sin embargo, no existen evidencias empíricas concluyentes que vinculen a los PTC con aumentos en el capital humano, porque una mayor participación en el sistema educacional no produce necesariamente dichos aumentos. Para establecerlo será necesario utilizar indicadores asociados al rendimiento escolar.
} 
Este desafío implica, según los casos, el diseño, organización, y fortalecimiento de los sistemas para la superación de la pobreza y la indigencia (o pobreza extrema) articulados alrededor de tres elementos básicos: (1) apoyo a los ingresos (transferencias monetarias); (2) servicios sociales de buena calidad; y (3) medidas específicas para la inclusión productiva.

También se ha adquirido conciencia sobre el hecho de que la salida sostenible de la pobreza implica un proceso complejo y requiere de políticas de Estado de mediano y largo plazo sostenidas en pactos sociales y fiscales que involucren a los principales actores políticos, económicos y sociales, y que viabilicen la legitimación y financiación de dichas políticas.

Por ende, la disminución de la desigualdad es un desafío que le corresponde tanto a las instituciones responsables de lo social (Ministerios de Desarrollo Social, etc.) como a las entidades encargadas de las políticas económicas y productivas (Ministerios de Hacienda, Economía, Agricultura, Infraestructuras, etc.). Así, entre lo social y lo económico hay una relación fundamental: lo social sin lo económico no puede alcanzar cambios permanentes en la lucha contra la pobreza y para la equidad; así como lo económico sin lo social no puede garantizar el desarrollo integral y la inclusión social de un número elevado de ciudadanos. Teniendo en cuenta además, que las políticas sociales también contribuyen positivamente al crecimiento económico.

Por lo anterior, es necesario tomar nota de que, además de las contribuciones pagadas por los ciudadanos que tienen un trabajo formal, una parte del gasto para la protección social tendrá que fundamentarse en otras fuentes, empezando por la fiscalidad general (Cecchini \& Martínez, 2011, pp. 67-72).

En este marco, la consolidación de los sistemas de protección social como políticas públicas con financiamiento sostenible, necesita: (a) impulsar programas de comunicación y difusión orientados a la ampliación del consenso hacia la priorización de la inversión social, y (b) enfatizar el valor agregado que la inclusión social representa para cada país en su conjunto, incluidos el sector privado y los ciudadanos de mayores ingresos.

Finalmente, la inclusión social y productiva tiene que asumir como horizonte estratégico el trabajo decente (empleo digno y remuneración adecuada), evitando la reproducción de las desigualdades al interior del mercado laboral, evidenciadas a menudo por la existencia de trabajos temporales, inestables y mal pagos.

\section{Logros y desafíos de la lucha contra la pobreza en Colombia}

En los últimos años Colombia ha logrado avances significativos en la lucha contra la pobreza, tanto en lo referente a la disminución del número de personas pobres, la estructuración de una institucionalidad y una legislación más orgánicas, y la formulación e implementación de políticas más efectivas. 
Sin olvidar que estos logros están relacionados también con otros factores ${ }^{4}$, el programa Más Familias en Acción (MFA) liderado por el Departamento para la Prosperidad Social (DPS), ha representado la punta de lanza de una acción estatal de gran envergadura. Baste decir que en el período 2010-2013 MFA alcanzó la cobertura de unos 2,65 millones de familias y un gasto anual de alrededor de 1,5 billones de pesos.

Sin embargo, en Colombia las políticas públicas orientadas a la inclusión social se encuentran frente a unos desafíos que hay que encarar adecuadamente a todo nivel. Entre ellos, este texto aborda los siguientes: (1) Articulación entre PTC y sistema de protección social, con énfasis en la formulación y gestión de las estrategias de egreso, por un lado, y de las condicionalidades, por el otro; (2) Ruralización de la lucha contra la pobreza; (3) Interconexión de los PTC con estrategias orientadas a la inclusión productiva, la generación de ingresos y la adquisición de habilidades blandas; (4) Atención a los adultos mayores y ampliación de la cobertura de pensiones no contributivas, sobre todo en las áreas rurales; y (5) Abordaje de los temas organizacionales y gerenciales representados por la coordinación interinstitucional, el enfoque intersectorial y los sistemas informativos. A continuación se presenta un breve análisis para cada uno de ellos.

\section{Articulación entre PTC y sistemas de protección social}

Los PTC realizados hasta la fecha en América Latina muestran ambigüedades y debilidades en la definición de las estrategias de egresos de los usuarios de este tipo de programas (Rangel, 2011, pp. 20-21), que a su vez indican una insuficiente articulación entre estos y los sistemas de protección social.

¿Cuáles son las condiciones para egresar de los PTC? Es una pregunta que aún no tiene respuestas coherentes debido a que no resulta fácil determinar las reglas de salida de programas que combinan objetivos de corto, mediano y largo plazo.

Se han ordenado las distintas estrategias de egreso en tres tipologías según las cuales este se produce por: (1) superación de la pobreza (Brasil, Ecuador, Argentina); (2) cumplimiento de las reglas de transición (México y Chile); y (3) vencimiento del tiempo de permanencia previsto o pérdida de las condiciones de elegibilidad (Nicaragua, Perú y El Salvador). A esta tipología escapan, en parte, experiencias como la de Colombia, donde el egreso se da de manera distinta según el tipo de programa, o sea la culminación de los estudios secundarios del hijo menor de la familia beneficiaria en el caso de MFA y la superación de la pobreza según parámetros e indicadores sujetos

\footnotetext{
${ }^{4}$ Como por ejemplo el crecimiento del producto interno bruto que entre 2002 y 2012 ha sido de $4,3 \%$ anual, el aumento de las exportaciones y otros indicadores macroeconómicos positivos.
} 
a verificación periódica en el caso de la estrategia Red Unidos ${ }^{5}$, implementada por la Agencia Nacional para la Superación de la Pobreza Extrema (ANSPE).

El egreso por vencimiento del tiempo previsto para ser usuario del programa no responde a ningún criterio asociado al cumplimiento de objetivos. En este caso pareciera que la salida de los programas tiene más bien relación con sus limitaciones financieras. El cumplimiento de reglas de transición, como en el caso del programa Chile Solidario, parece ser una condición de egreso más coherente con los objetivos de largo plazo de los PTC porque se inserta en una estrategia continua de oferta de protección social.

La forma como los distintos países resuelvan los mecanismos de egreso puede marcar la ubicación de los PTC en los distintos enfoques de protección social existentes en la región: manejo social del riesgo, mercado del trabajo, y perspectiva de derechos.

Volviendo al caso colombiano, se podría decir que MFA solo cuenta con unas reglas de salida pero no con una estrategia de egreso, mientras que la Red Unidos tiene una estrategia de egreso que incorpora una batería de indicadores muy formalizados. Tanto es así que la estrategia "Promoción social y siguiente paso", que se menciona en el Plan Nacional de Desarrollo 2010-2014, hasta el momento no ha sido formulada, por lo menos en lo referente al cumplimiento de los objetivos de MFA.

Según Tassara (2015):

\begin{abstract}
$\mathrm{Al}$ respecto, se puede avanzar la hipótesis que esta diferencia entre el programa MFA y la estrategia Red Unidos se explica por las diferentes misiones de las dos. Mientras que el primero es parte integrante del sistema de protección social, la segunda es una estrategia de coordinación interinstitucional orientada a focalizar la atención de la institucionalidad pública hacia la facilitación del acceso preferente a la oferta pública y privada de bienes y servicios a los sectores más pobres de la población colombiana. Además, las metas de la Red Unidos fueron formuladas para el logro de un resultado concreto, o sea la graduación de 350.000 familias de la indigencia entre 2012 y 2014, en un plazo de tiempo relativamente corto. (p.36)
\end{abstract}

En síntesis, la experiencia de los PTC latinoamericanos muestra que a menudo la salida de la pobreza puede ser temporal y que para conseguir resultados estables es necesario trabajar en el largo plazo en la implementación de políticas de Estado, de manera que el egreso asociado al cumplimiento de ciertos indicadores, no resulta coherente con la coexistencia de objetivos de reducción de la pobreza en el corto plazo y otros orientados a interrupción de la pobreza inter-generacional en el largo plazo. Es decir, la superación de un umbral de pobreza da cuenta del cumplimiento del objetivo de corto plazo pero no

\footnotetext{
${ }^{5} \mathrm{~A}$ pesar de que la Red Unidos no es propiamente un PTC, desempeña un papel fundamental en la estrategia de la lucha contra la pobreza del gobierno colombiano.
} 
asegura que se cumpla el objetivo de largo plazo. Por lo demás, es sabido que los vaivenes económicos pueden hacer recaer a una familia pobre en la extrema pobreza, por lo que la condición que significó la salida del programa puede revertirse en pocos meses.

Por lo tanto, el elemento central para la sostenibilidad en el largo plazo de un estrategia de salida de la pobreza es la existencia de un sistema de protección social que: (a) esté basado en principios de universalidad y orientado a la garantía de derechos; (b) tenga una vocación inclusiva; (c) sea muy estructurado desde el punto de vista institucional; y (d) cubra la oferta de los servicios más necesitados por la población. Tanto es así que progresivamente, en América Latina ha aumentado el número de PTC que opera como puente hacia los servicios de protección social (Gráfico 2).

\section{Gráfico 2. PTC latinoamericanos que operan como puente hacia los servicios del sistema de protección social}

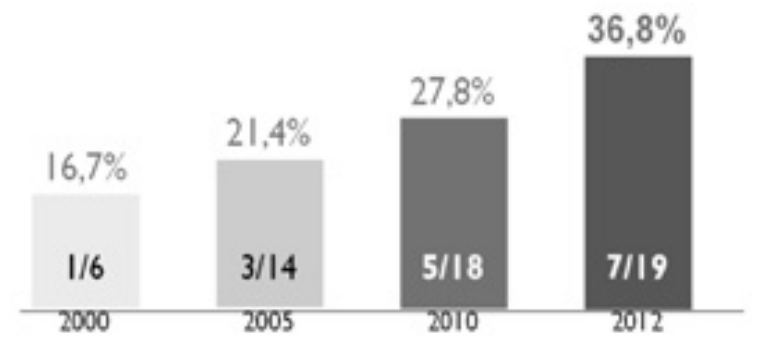

Fuente: Elaboración propia fundamentada en la base de datos CEPAL de programas de protección social no contributiva en América Latina y el Caribe

También parece oportuno replantear, al menos parcialmente, la función y aplicación de las condicionalidades. Sin menoscabo de su vocación inicial, que es la de impactar sobre los comportamientos de las familias beneficiarias para que asuman conductas orientadas a la consolidación de su capital humano, en algunos países se empiezan a utilizar también como indicador de vulnerabilidad. Por ejemplo en Brasil y Chile el incumplimiento de las condicionalidades se asume como señal de alarma para la activación de un servicio de acompañamiento ad hoc para las familias. En el caso del Programa Bolsa Familia (PBF) de Brasil los beneficiarios que no logren cumplir las condicionalidades pueden recurrir al apoyo del gestor municipal del programa, a los Centros de Referencia de la Asistencia Social (CRAS) o a los Centros de Referencia Especializados de Asistencia Social (CREAS). Claro está que si las familias no logran revertir el incumplimiento en un cierto tiempo, pueden incurrir en la suspensión o hasta en la cancelación de los beneficios ofrecidos por el programa (Ibarra, 2014, p. 6).

Otro elemento de la discusión es el ingreso mínimo garantizado. Entre los pocos países que ya lo adoptaron se encuentra Brasil, donde la Ley 10.835 que introdujo la Renta Básica 
de Ciudadanía ${ }^{6}$, fue aprobada un día antes de la Ley 10.836 del 9 de enero de 2004, que sancionó la adopción del PBF como política pública del Estado. La Ley 10.835 establece el derecho de todos los ciudadanos, brasileños y extranjeros que vivan en el país desde por lo menos cinco años -sin importar su condición socioeconómica- de recibir anualmente un monto cuyo valor debe ser igual para todos y suficiente para mantener los gastos mínimos de alimentación, educación y salud. A pesar de su universalidad, la renta básica empezó a ser aplicada de forma gradual a partir de 2005, a criterio del poder executivo, dándole prioridad a los grupos más necesitados de la población. Para establecer el valor de la renta básica se tienen en cuenta el nivel de riqueza alcanzado a nivel nacional y la disponibilidad presupuestaria (Castro, 2013; Ibarra, 2014, pp. 21-22).

El anterior es un tema controvertido. Según algunos analistas los PTC tendrían que convertirse paulatinamente en una política pública que garantice una renta básica ciudadana, siendo esta la manera más eficaz para erradicar la pobreza (Casassas \& Raventós, 2011; van Parijs \& Vanderborght, 2006; Raventós, 2001). Otros subrayan sus altos costos. Graziano da Silva y Tavares (2010, p. 256) sintetizan el estado del arte de la discusión de la siguiente forma:

Transformar el PBF en renta mínima significaría superar su carácter de emergencia y de transición para que las familias pasen de un estado de pobreza a uno de no pobreza. Al mismo tiempo, la transformación implicaría un costo financiero difícilmente sostenible, especialmente con el aumento de la volatilidad financiera que se ve en el mundo actual y futuro. Del lado sociopolítico, tal transformación depende de un amplio consenso que aún no existe.

\section{Ruralización de la lucha contra la pobreza}

\section{Gráfico 3. Pobreza e indigencia en Colombia (\% población)}

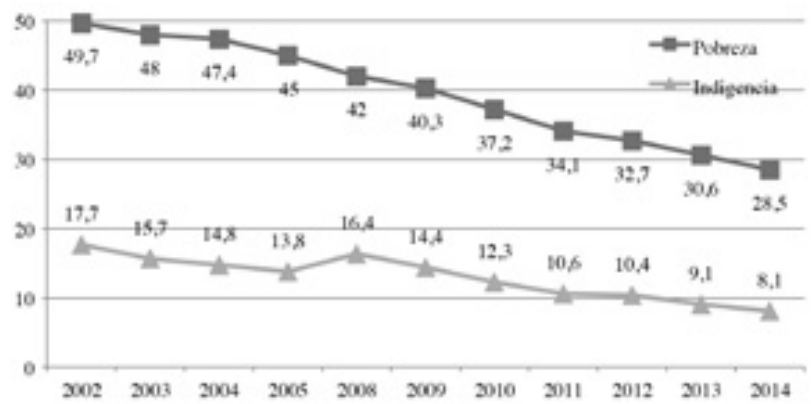

Fuente: DANE (2015)

${ }^{6}$ En Brasil, antes de la aprobación de la ley mencionada, el antecedente más significativo fue la implementación desde 1991 del Programa de Garantía de Renta Mínima. 
En Colombia, desde el 2002 hasta el 2014 la pobreza monetaria disminuyó del 49,7\% al 28,5\% y la pobreza multidimensional ${ }^{7}$ pasó de 49,2\% a 21,9\% (DANE, 2015) ${ }^{8}$. Sin embargo, se observan variaciones importantes entre las áreas urbanas y las rurales (Gráfico 4).

\section{Gráfico 4. Pobreza e indigencia en Colombia discriminada por zonas urbanas y rurales (\% población)}

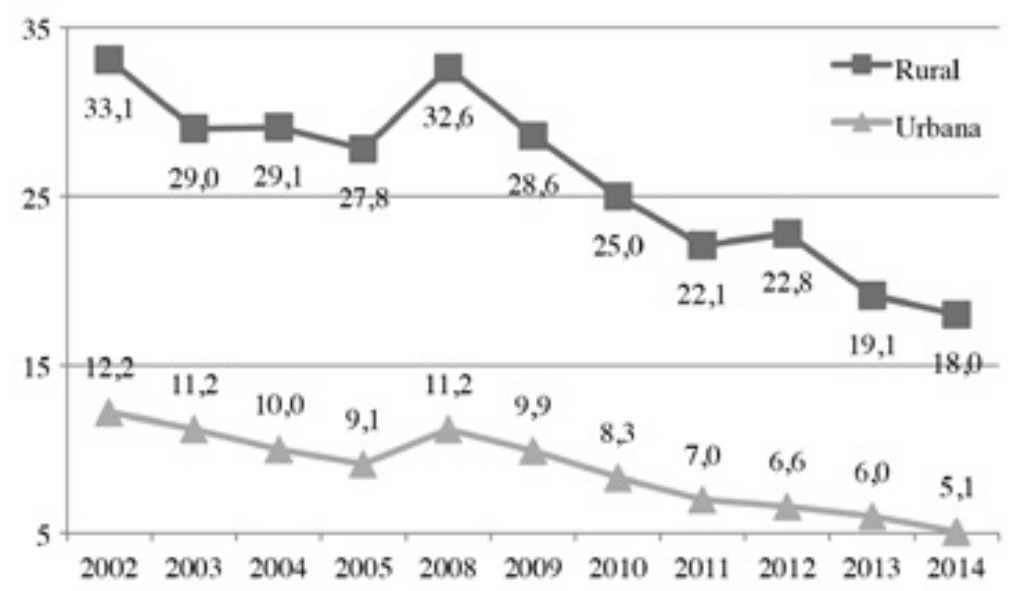

Fuente: DANE (2015)

La reducción de la pobreza monetaria es más notoria en las ciudades mientras que en las áreas rurales disminuyó más la pobreza multidimensional. Al mismo tiempo, entre 2011 y 2014, en las zonas rurales se observa una desaceleración en la reducción de la pobreza y la indigencia (DANE, 2015). Aunque la reducción de la pobreza monetaria y multidimensional se observa tanto en las ciudades como en el campo, los datos indican que la brecha rural/urbana en la incidencia de la pobreza monetaria ha aumentado, especialmente en lo referente a la indigencia. En 2002 la pobreza monetaria rural era 1,36 veces la urbana, mientras que en 2012 la pobreza rural fue 1,68 veces mayor de la urbana. Por otro lado, como se aprecia en el gráfico 5, esta dinámica resulta aún más evidente si se compara la evolución de la indigencia.

\footnotetext{
${ }^{7}$ La pobreza monetaria se basa en la "medición de los ingresos per cápita de la unidad de gasto y su relación con la línea de pobreza y pobreza extrema" (DANE, 2013, p. 2), mientras que la medición de la pobreza multidimensional se basa en variables que dan cuenta de la situación del hogar en relación con la educación, la salud, el empleo, la primera infancia y la infraestructura disponible. ${ }^{8} \mathrm{Al}$ respecto, Bogliacino y Muñoz $(2015$, p. 7$)$ observan que "En general, los umbrales que se usan para clasificar los grupos sociales son poco transparentes. La línea de pobreza, que recientemente ha recibido algunos cambios, tiende a subestimar ese flagelo $[\ldots] "$.
} 


\section{Gráfico 5. Relación entre indigencia rural y urbana}

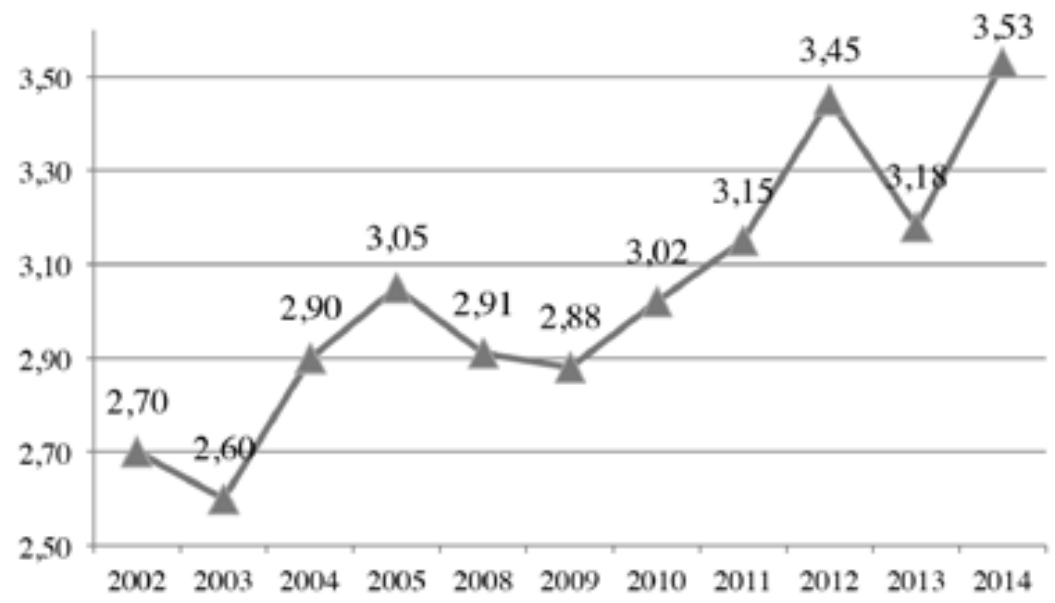

Fuente: DANE (2015)

En el período considerado la relación en la incidencia de la indigencia en las áreas rurales y urbanas ha aumentado de forma continua y ha pasado de 2,7 en 2002 a 3,53 en 2014 (Gráfico 5).

Al mismo tiempo, Colombia debe mejorar sustancialmente en la redistribución de la riqueza, ya que la desigualdad es una de las más altas del mundo, con un índice de Gini de o,538 en 2014 (DANE, 2015).

Es necesario mencionar también que al hablar de pobreza, es ineludible abordar las problemáticas del desplazamiento y de los grupos étnicos, teniendo en cuenta que entre 1985 y 2012 ha habido más de cinco millones y medio de desplazados (CODHES, 2013, p. 12), sobre todo en el medio rural, y que la población indígena se caracteriza por sus altos índices de indigencia. Con una población de 1.378 .884 personas que representa $3,4 \%$ del total nacional y de procedencia predominantemente rural (78\%), 63\% de los indígenas se ubican debajo de la línea de pobreza. De este grupo 47,6\% está por debajo de la línea de la indigencia (El Espectador, 2012).

Frente a esta situación, es necesario profundizar la ruralización de MFA, dándole continuidad a lo que se hizo entre 2011 y 2012 con el rediseño del programa Familias en Acción y la formalización del programa vigente ${ }^{9}$. A manera de ejemplo, el incremento

\footnotetext{
${ }^{9}$ A nivel operativo, el rediseño generó un mayor cubrimiento de la población y una mayor asignación de recursos en las zonas con alta incidencia de pobreza, así como para las familias ubicadas en los municipios más pobres del país, aumentando la presencia y la acción del programa en las zonas rurales.
} 
de la cobertura en tres de los departamentos más pobres del país fue de $52 \%$ en Chocó, $48 \%$ en Nariño y $39 \%$ en Cauca. Lo anterior se logró gracias a medidas como las siguientes: (1) firma de convenios con las alcaldías, que se asociaron más fuertemente a la ejecución del programa; (2) aumento de los operadores autorizados, seleccionados a través de licitaciones que tuvieron más en cuenta la dimensión regional y facilitaron la descentralización de las actividades; y (3) adopción de distintas alternativas para efectuar los pagos, lo que permitió incluir a zonas en las cuales no había sucursales bancarias (DPS, 2013, pp. 49-51).

En este marco, resulta prioritario reorientar la focalización hacia los municipios con mayor vulnerabilidad social, económica, infraestructural y cultural. Por esto se considera útil abordar el tema desde dos enfoques: (a) la articulación entre las políticas de desarrollo rural, agrícola y social, involucrando de forma consistente los Ministerios competentes (agricultura y desarrollo rural, salud y protección social, infraestructura, trabajo, entre otros); y (b) el reajuste del tamaño de las acciones, reduciendo el número de programas y concentrando los recursos en algunas acciones integrales que permitan conjugar las finalidades de desarrollo económico en el corto plazo con un cambio de la vocación y percepción del área rural en el mediano y largo plazo.

Finalmente, cabe mencionar la experiencia de Brasil que ha acompañado la implementación del PBF con la adopción de medidas específicas para impulsar el desarrollo de la agricultura familiar y fomentar la generación de ingresos en las áreas rurales. Entre ellas, se pueden recordar las siguientes: (i) la asunción de la agricultura familiar como prioridad para el desarrollo rural (desde 1990) y la consecuente creación de dos Ministerios separados: uno de Agricultura y otro de Desarrollo Agrario ${ }^{10}$, con una Secretaría de Agricultura Familiar dedicada específicamente al fomento de la misma; (ii) la creación en 1995 del Programa Nacional de Fortalecimento da Agricultura Familiar (PRONAF) que viabilizó la disminución de la tasa de interés para el crédito a la pequeña agricultura del 16\% al 9\% anual y está ofreciendo la capacitación, orientación y acompañamiento en la definición e implementación del plan de negocios a los pequeños agricultores; (iii) la activación en 2003 y en el marco del PRONAF, del Programa de Aquisição de Alimentos (PAA) y del Programa Garantia-Safra (PGS). El PAA es considerado una de las principales acciones estructurales del Programa Fome Zero y es coordinado por la Secretaria Nacional de Segurança Alimentar e Nutricional (SESAN) del Ministério de Desenvolvimento Social e Combate à Fome (MDS). Este programa ofrece apoyo a los pequeños agricultores, compra los productos de la agricultura familiar y los comercializa utilizando una parte de los mismos para atender a las familias en riesgo alimentario.

\footnotetext{
${ }^{10}$ En el caso brasileño, hasta que los dos ministerios estuvieron juntos, el peso político de grandes agricultores impedía el avance de la agricultura familiar.
} 
El PGS consiste en un seguro que se ofrece en condiciones especialmente ventajosas a los pequeños agricultores afectados por las malas cosechas causadas por fenómenos atmosféricos adversos (Ibarra, 2014, pp. 15-18).

Inclusión productiva y generación de ingresos

\section{Gráfico 6. PTC latinoamericanos que incluyen un componente relevante de inclusión laboral y económica}

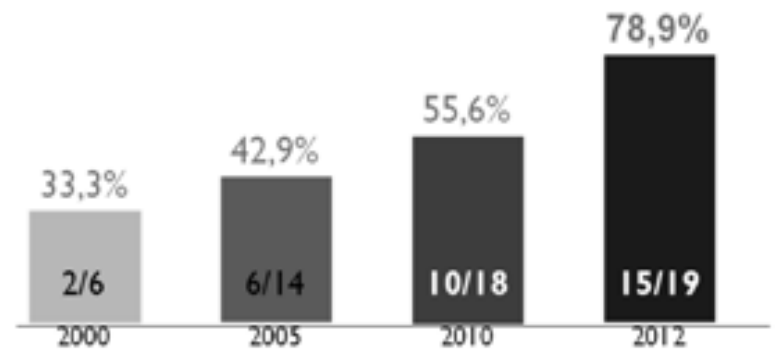

Fuente: Elaboración propia fundamentada en la base de datos CEPAL de programas de protección social no contributiva en América Latina y el Caribe

Como se puede apreciar en el gráfico 6, la importancia de la inclusión productiva y la generación de ingresos se ha reflejado en su progresiva incorporación en la gran mayoría de los PTC que se están realizando en América Latina.

En lo referente a Colombia, en los últimos años muchas instituciones han abordado el tema de las habilidades blandas $(\mathrm{HB})^{11}$ con atención específica a los programas y a las intervenciones volcadas a fomentar la inclusión productiva y la generación de ingresos con población pobre y vulnerable. Estas habilidades se consideran directamente funcionales a la mejora de las condiciones de empleabilidad. Lo anterior se fundamenta en bases empíricas que muestran cómo la inserción laboral y productiva formal de los beneficiarios de los programas sociales es frágil e inestable. Por ejemplo en el caso del PBF de Brasil, Leichsenring (2010) evidencia que la permanencia promedio en los empleos formales es significativamente menor para los beneficiarios (11,3 meses) respecto a los no beneficiarios (22,8 meses) del programa. Esto no parece relacionado con la falta de competencias técnicas sino con la fragilidad en las competencias psicosociales necesarias para el manejo de las dinámicas y relaciones en el ámbito productivo.

\footnotetext{
11 "Las habilidades blandas son las competencias profesionales que se desarrollan durante la vida a través del aprendizaje y se expresan en el ambiente laboral después de una exposición al mismo. Dentro de estas se encuentran la iniciativa, delegación, capacidad de comunicación además del análisis y resolución de problemas, entre otras" (DNP 2013, p. 16).
} 
Como es evidente, las HB constituyen un recurso estratégico para que el sistema de competencias y habilidades técnicas puedan expresarse operativamente en cuanto a profesionalidad adecuada al rol. $\mathrm{Y}$ es justamente la capacidad de adecuar al rol la profesionalidad que se posee, lo que determina el potenciamiento de los niveles de empleabilidad de los individuos. Además, hay que considerar que el mercado laboral es generador y reproductor de condiciones de desventaja y desigualdad entre sus participantes y esta dinámica evidencia aún más la necesidad de una inversión para el fortalecimiento de las $\mathrm{HB}$ en la población pobre y vulnerable. Con respecto a este tema el debate y la acción de las diferentes entidades e instituciones colombianas son muy ricos y diferenciados, como se aprecia en la tabla siguiente.

\section{Tabla 1. Enfoques y actividades en lo referente a las competencias psicosociales y socio-laborales}

\begin{tabular}{|c|c|c|}
\hline Institución & Enfoque & Actividades \\
\hline $\begin{array}{l}\text { Ministerio del } \\
\text { Trabajo }\end{array}$ & $\begin{array}{l}\text { Inclusión de competencias } \\
\text { básicas y transversales en } \\
\text { programas de formación para } \\
\text { trabajadores. }\end{array}$ & $\begin{array}{l}\text { Proyecto piloto "Estrategia pedagógica con } \\
\text { instituciones de formación para el trabajo". } \\
\text { Involucramiento de empresas para la } \\
\text { identificación de competencias básicas y } \\
\text { transversales prioritarias. }\end{array}$ \\
\hline DPS & $\begin{array}{l}\text { Inversión en competencias } \\
\text { psicosociales y socio-laborales } \\
\text { como componente transversal } \\
\text { de programas como Jóvenes } \\
\text { en Acción e Ingreso para la } \\
\text { Prosperidad Social (con el } \\
\text { apoyo de EUROsociAL). } \\
\end{array}$ & $\begin{array}{l}\text { Identificación de las competencias } \\
\text { psicosociales y socio-laborales prioritarias. } \\
\text { Identificación de instrumentos de medición y } \\
\text { diseño de procesos de evaluación. } \\
\text { Alianzas público privadas y articulación } \\
\text { intersectorial. }\end{array}$ \\
\hline DNP & $\begin{array}{l}\text { Análisis, investigación y } \\
\text { planeación (con el apoyo de } \\
\text { EUROsociAL). }\end{array}$ & $\begin{array}{l}\text { Elaboración de un documento de } \\
\text { fundamentación teórica. } \\
\text { Animación de una mesa interinstitucional } \\
\text { sobre el tema. }\end{array}$ \\
\hline SENA & \begin{tabular}{|l} 
Implementación de \\
competencias básicas \\
transversales y sociales en los \\
currículos del SENA, con miras \\
a una formación profesional \\
integral de calidad. \\
\end{tabular} & $\begin{array}{l}\text { Elaboración de un documento de } \\
\text { fundamentación teórica y pedagógica. } \\
\text { Identificación de un listado de competencias } \\
\text { prioritarias. } \\
\text { Identificación de instrumentos de medición. }\end{array}$ \\
\hline $\begin{array}{l}\text { Ministerio de } \\
\text { Cultura }\end{array}$ & $\begin{array}{l}\text { Desarrollo humano como } \\
\text { realización del potencial } \\
\text { biológico, traducido en } \\
\text { términos de ser social y } \\
\text { cultural de la persona. } \\
\end{array}$ & $\begin{array}{l}\text { Programa de emprendimiento cultural e } \\
\text { innovación para la prosperidad "Emprende } \\
\text { cultura". } \\
\text { Propuesta de talleres temáticos. }\end{array}$ \\
\hline $\begin{array}{l}\text { Consejo } \\
\text { Noruego para } \\
\text { Refugiados }\end{array}$ & $\begin{array}{l}\text { Fortalecimiento de habilidades } \\
\text { para la vida en el marco de } \\
\text { proyectos de emergencia } \\
\text { humanitaria. }\end{array}$ & $\begin{array}{l}\text { Proyecto "Fortalecimiento de competencias } \\
\text { para la vinculación de jóvenes desplazados } \\
\text { y con mayor vulnerabilidad al mundo } \\
\text { productivo y social". } \\
\text { Articulación y gestión de alianzas con el sector } \\
\text { empresarial y entidades que realizan acciones } \\
\text { de Formación para el Trabajo y Generación de } \\
\text { Ingreso. }\end{array}$ \\
\hline
\end{tabular}




\begin{tabular}{|l|l|l|}
\hline Institución & \multicolumn{1}{|c|}{ Enfoque } & \multicolumn{1}{c|}{ Actividades } \\
\hline Banco Mundial & $\begin{array}{l}\text { Empoderamiento de las } \\
\text { mujeres jóvenes afectadas } \\
\text { por las violencias. }\end{array}$ & $\begin{array}{l}\text { Proyecto de capacitación y asistencia técnico- } \\
\text { financiera: apropiación de herramientas } \\
\text { para la promoción del empoderamiento, la } \\
\text { cohesión social y la independencia económica. }\end{array}$ \\
\hline $\begin{array}{l}\text { ICBF - } \\
\text { Subdirección } \\
\text { de Resp. } \\
\text { Penal }\end{array}$ & Habilidades para la vida. & $\begin{array}{l}\text { Acompañamiento psicosocial y procesos } \\
\text { pedagógicos orientados a la elaboración de } \\
\text { proyectos de vida. }\end{array}$ \\
\hline $\begin{array}{l}\text { ICBF - } \\
\text { Dirección de } \\
\text { Protección }\end{array}$ & $\begin{array}{l}\text { Habilidades para la vida y } \\
\text { competencias psicosociales. }\end{array}$ & $\begin{array}{l}\text { Atención psicosocial a la niñez víctimas del } \\
\text { conflicto armado interno. }\end{array}$ \\
\hline
\end{tabular}

Fuente: Elaboración propia con base en EUROsociAL (2013) y DNP (2013).

La tabla anterior manifiesta que en Colombia la abundante reflexión y acción en el fortalecimiento de las competencias psicosociales en la población pobre y vulnerable es muy dispersa y está basada en lógicas de programa más que en políticas públicas integradas. Por ende, aunque la constitución de la Mesa interinstitucional sobre habilidades blandas como espacio de coordinación representa una mejora, queda vigente la necesidad de avanzar hacia la elaboración de una política que impulse el fortalecimiento de las competencias psicosociales como componente transversal de un sistema de protección social en el que el acompañamiento psicosocial sea un servicio de base articulado territorialmente y en coordinación con los programas de generación de ingreso e inclusión social (Más Familia en Acción, otros PTC, Red Unidos, etc.).

\section{Adultos mayores y sistema pensional}

A pesar de algunas excepciones, la historia de América Latina está caracterizada por un esfuerzo limitado en la prevención de la pobreza en la tercera edad y la mayoría de los sistemas atienden a la población con una trayectoria laboral relativamente estable. Por su parte, los escasos programas no contributivos existentes brindan una protección limitada y de carácter asistencial que no corresponde a un principio de universalidad. Sin embargo, muchos PTC incluyen programas y prestaciones específicas para los adultos mayores. Entre ellos ${ }^{12}$ vale la pena mencionar el "Beneficio de Prestação Continuada" en Brasil, el "Programa 70 y más" y la "Pensión alimentaria DF" en México, la "Pensión básica solidaria" en Chile, la "Pensión para adultos mayores" en Ecuador, el "Bono Solidario" (Bonosol) en Bolivia ${ }^{13}$; la "Pensión básica universal para la persona adulta" en El Salvador, el "Bono tercera edad” en Honduras, el “Apoyo a adultos mayores” en

${ }^{12}$ Con excepción a El Salvador cuyo grupo meta son los adultos mayores de 70 años, todos los demás están dirigidos a personas mayores de 65 años.

${ }^{13}$ Desde 1997 el Bonosol brinda una pensión universal a todos los mayores de 65 años, independientemente de su historia contributiva o nivel socioeconómico. Este programa ha permitido 
Paraguay y en la República Dominicana (Cecchini \& Madariaga, 2011, pp. 18-25). La mayoría de ellos otorga una pensión de tipo no contributivo que no está supeditada al cumplimiento de condicionalidades. Los casos más interesantes son los de Brasil, México y Chile (Bertranou, Solorio, \& van Ginneken, 2002; Bosch, Melguizo, \& Pagés, 2013).

El Beneficio de Prestação Continuada (BPC) de Brasil es una pensión no contributiva para adultos mayores y personas con discapacidad en situación de pobreza. El BPC se estableció en la Constitución de 1988 como derecho constitucional ${ }^{14}$ y por ende debe otorgarse a toda persona que cumpla el criterio de elegibilidad. El BPC es parte de la Política de Asistencia Social en el marco de la Protección Social Básica ofrecida por el Sistema Único de Assistência Social (SUAS) y es administrado por el Ministério do Desenvolvimento Social e Combate à Fome (MDS), a través de la Secretaria Nacional de Assistência Social (SNAS), e implementado por el Instituto Nacional do Seguro Social (INSS), que se responsabiliza también de la coordinación, regulación, financiación, monitoreo y evaluación de todas las actividades respectivas.

Este beneficio está dirigido a los ancianos mayores de 65 años que tengan un ingreso familiar inferior a un cuarto de salario mínimo y a las personas portadoras de deficiencia que las incapaciten para el trabajo y no puedan tener una vida independiente. Cada destinatario tiene que demostrar que ni él ni su familia están en condición de responder por sus necesidades y está prevista una revisión bianual de los requisitos. El valor del pago, que es individual e intransferible en caso de muerte del beneficiario, es de un salario mínimo vigente mensual (art. 34 Ley 10.741/2003). En 2012 el beneficio fue concedido a 4 millones de personas, de las cuales $45 \%$ eran ancianos y $55 \%$ portadores de deficiencia. En el mismo año se gastaron $\mathrm{R} \$ 30.300$ millones para el BPC y $\mathrm{R} \$ 20.500$ millones $^{15}$ para las 13.9 millones de familias atendidas a través del PBF. Se deduce entonces que BPC implica un costo superior a un 50\% de lo que se invierte para el PBF (Ibarra, 2014, p. 7).

El BPC aplica también a los trabajadores rurales hombres mayores de 60 (hombres) y trabajadoras rurales mujeres mayores de 55, representa un ejemplo importante en materia de extensión de la cobertura previsional mediante mecanismos no contributivos. Sus características principales son las siguientes: (1) Está vinculado a un período mínimo de actividad en el sector agrícola (12 años); (2) Se financia parcialmente con impuestos

\footnotetext{
aumentar la cobertura previsional de un país cuya cobertura contributiva es relativamente baja, aunque sus beneficios hayan ido decreciendo con el tiempo (Gamboa, 2006).

${ }^{14}$ Este derecho fue reglamentado por la Lei Orgânica da Assistência Social (LOAS), Ley 8.742 del 07/12/1993, las Leyes 12.435 del 06/07/2011, 12.470 del 31/08/2011 y 10.741 del 01/10/2003, que modificaron la LOAS, y los Decretos 6.214 del 26/09/2007 y 6.564 del 12/09/2008.

${ }_{15}$ Con base en el cambio vigente, lo anterior corresponde respectivamente, a 25,452 y 17,220 billones de pesos colombianos.
} 
a la comercialización de productos agrícolas (de ahí la denominación por algunos autores de programa semicontributivo); y (3) Es una forma de pensión no contributiva con focalización por área geográfica y que ha permitido reducir enormemente la pobreza en zonas tradicionalmente rurales como el nordeste del país ${ }^{16}$.

Otro caso interesante es el de Chile donde a comienzos de este siglo se detectó la existencia de varias lagunas que no habían sido consideradas en el diseño del sistema pensional y que generaban una insuficiente cobertura del mismo. Frente a esta situación, el primer gobierno de la Presidenta Bachelet creó un pilar solidario que "en la práctica, [...] significó la transformación del sistema de seguridad chileno en uno mixto, que combina elementos de capitalización individual y transferencias monetarias del Estado" (Huepe \& Larrañaga 2010, p. 158).

En particular, se introdujo la Pensión Básica Solidaria de vejez (PBS) que se otorga a hombres y mujeres mayores de 65 años con veinte años de residencia en Chile, que no reciban una pensión contributiva y que pertenezcan al 60\% de la población de menores recursos. Asimismo, la PBS de invalidez se otorga a personas entre 18 y 65 años que tengan algún tipo de discapacidad física o mental y cumplan los demás requisitos anteriormente señalados. Como complemento, también se creó el Aporte Previsional Solidario de vejez e invalidez. Para el caso de vejez, este beneficia a los pensionados que reciben mensualmente un monto menor a 472 dólares, mientras que para la invalidez, beneficia a quienes reciben pensiones menores a 139 dólares, hasta alcanzar dicha suma total. La implementación de este sistema se realizó de forma gradual entre 2008 y 2011 (Vargas, 2014, pp. 16-17).

Finalmente, en el caso de México existen varios programas que benefician directa o indirectamente, a los adultos mayores (Rubio \& Garfias, 2010, pp. 20-22). En primer lugar, desde 2006 las familias beneficiarias de Oportunidades, que residen en localidades con más de 20.000 habitantes y tienen miembros de 70 años o más ${ }^{17}$, reciben un apoyo monetario adicional por cada uno de ellos ( $\$ 345$ mensuales $^{18}$ ), con la única condicionalidad de asistir a citas médicas semestrales. El monto de la transferencia se ajusta semestralmente con base en la variación del Índice Nacional de Precios de la Canasta Básica y cuando una familia está integrada solo por adultos mayores, a la transferencia

\footnotetext{
${ }^{16}$ Sin embargo, se estima que aún hay cerca de tres millones de personas que no acceden a la prestación rural por ser temporales sin lugar fijo de trabajo o residencia. Por ende, estos trabajadores no tienen forma de documentar su actividad o de contribuir a la seguridad social.

${ }^{17}$ Oportunidades también proporciona a los integrantes de las familias beneficiarias un paquete de servicios de salud gratuitos de acuerdo al grupo de edad, sexo y evento de vida, a través de citas programadas. En el caso de los adultos mayores de 60 años, el paquete incluye acciones de promoción de la salud y detección de enfermedades tales como diabetes, hipertensión arterial, deficiencias visuales y auditivas, deterioro cognitivo, entre otras (Rubio \& Garfias, 2010, p. 20).

${ }^{18}$ El cambio vigente es de unos 145 pesos colombianos para cada peso mexicano.
} 
básica se añade la entrega de apoyos alimentarios, energéticos y compensatorios, que llegan a unos \$450 mensuales por familia.

Además, desde 2007 los adultos mayores que residen en localidades con más de 30.000 habitantes pueden participar en el "Programa 70 y más" que transfiere $\$ 580$ mensuales sin condicionalidades. Sin embargo, para evitar duplicidades, sus beneficiarios deben renunciar al apoyo ofrecido por Oportunidades. Además del apoyo económico, el programa, que es implementado directamente por la Secretaría de Desarrollo Social, incluye acciones de promoción y participación social, y de coordinación institucional.

El tercer programa es la "Pensión alimentaria DF" que reciben los adultos mayores de 70 años que residen en el Distrito Federal (DF). Lo maneja el Instituto para la Atención de los Adultos Mayores. En este caso el beneficio es de unos \$ 950 mensuales por persona y se otorga sin ninguna condicionalidad.

Es importante señalar que los programas antes mencionados fueron diseñados e implementados teniendo en cuenta las características del sistema de pensiones prevaleciente en México (Rubio \& Garfias, 2010, pp. 34-36). Al respecto, si bien en el país existe una multiplicidad de sistemas dirigidos a la población empleada en el sector formal de la economía, menos de la tercera parte de la población adulta mayor recibe una pensión, mientras que la cobertura del sistema pensional es aún menor en las comunidades rurales e indígenas y prácticamente nula entre el 20\% más pobre de los mexicanos.

En el caso de Colombia no existen medidas pensionales específicas para los adultos mayores de las familias beneficiarias de MFA. Sin embargo, desde 2011 el Ministerio del Trabajo coordina la implementación del programa "Colombia Mayor" que busca proteger a las personas de la tercera edad que se encuentran desamparadas, no cuentan con una pensión o viven en la indigencia. A finales de 2013 este programa contaba con más de 1.25 millones de beneficiarios, que cada dos meses reciben un subsidio entre 40.000 y 75.0oo pesos mensuales para financiar sus necesidades básicas; está enfocado en alcanzar una cobertura de 2.4 millones de beneficiarios para 2018. Los recursos necesarios son otorgados por el Fondo de Solidaridad Pensional (FSP), mientras que la ejecución y seguimiento del programa se realiza en colaboración con las alcaldías municipales.

El FSP fue creado por la Ley 100 de 1993, está adscrito al Ministerio del Trabajo y tiene la finalidad de aumentar el nivel de las pensiones contributivas de los afiliados de bajos ingresos mediante aportes subsidiados por el Estado. En particular, el FSP -que recibe recursos públicos y aportes solidarios de los afiliados de mayores ingresos- subsidia en parte las cotizaciones de los trabajadores de escasos recursos. Pero estos subsidios están sujetos a la condición de realizar aportes a los sistemas contributivos, con la consecuente exclusión de los trabajadores marginados de los modelos formales.

Concretamente, el FSP financia la implementación del Programa de Subsidio al Aporte en Pensión (PSAP) que está destinado a los grupos poblaciones que no tienen 
acceso a los sistemas de seguridad social, tales como trabajadores independientes urbanos y rurales, desempleados, madres comunitarias y discapacitados, y concejales pertenecientes a municipios de categoría 4, 5 y 6. Para adherir al PSAP hay que aportar un porcentaje del monto total de cotización que oscila entre el $5 \%$ y el $30 \%$, dependiendo del grupo poblacional al que pertenezcan, mientras que el restante lo subsidia el gobierno nacional a través del consorcio "Colombia Mayor"19. Al vincularse al sistema la persona queda cubierta contra los riesgos de invalidez, vejez y muerte. En esta última, los sobrevivientes tienen derecho a recibir un auxilio funerario.

Con base en un estudio realizado por EUROsociAL y la OIT (Gasparini, Crosta, Haimovich, Álvarez, Ham, \& Sánchez, 2008), se puede concluir que:

En general, en América Latina la pobreza de los adultos mayores depende fuertemente del desarrollo del sistema de pensiones, que en la mayor parte de los países es de carácter contributivo y está basado en el empleo. Esto hace que solo aquellos individuos con empleo formal estable accedan a una jubilación al finalizar su ciclo laboral. (p. 7)

El estudio mencionado analizó la viabilidad económica (basada en la evaluación de los costos fiscales de mediano y largo plazo) y los impactos sociales sobre pobreza y desigualdad de la implementación de un piso de protección social no contributivo articulado alrededor de tres pilares (transferencias condicionadas, pensiones universales para adultos mayores y seguro de salud) en diez países de América Latina, incluida Colombia. Con este propósito, los autores realizaron una simulación de cinco posibles alternativas basados en los micro datos de las encuestas de hogares realizadas por los institutos nacionales de estadística de cada país. En lo referente a los programas de pensiones no contributivas (PNC), vale la pena destacar las siguientes conclusiones sobre la simulación realizada (Gasparini et al., 2008):

(1) En todos los países considerados las PNC focalizadas permitirían reducir significativamente la pobreza en la vejez a un costo razonable. En muchos casos el esfuerzo fiscal requerido representa una fracción insignificante del producto [interno bruto NdR]. Sin embargo, el efecto sobre la pobreza de la población total y la desigualdad es limitado; (2) Los resultados son robustos si se incorporan desincentivos a cotizar y filtraciones moderadas hacia la población no pobre. Respecto de los primeros, las conclusiones posiblemente serían diferentes si se consideraran programas universales, si los desincentivos se modelaran de

\footnotetext{
${ }^{19}$ Este consorcio está compuesto por Fiduprevisora SA, Fiducoldex SA y Fiducentral SA y tiene por objeto administrar los recursos del FSP en virtud del contrato de fiducia pública 216 de 2013 suscrito con el Ministerio del Trabajo.
} 
otra forma o si el monto de las pensiones otorgadas fuera mucho mayor. En particular, el carácter focalizado de las pensiones atenúa considerablemente estos desincentivos. (p. 9)

\section{Organización y gestión operativa}

Existen también factores de tipo organizacional y operativo que sería importante tener en cuenta para aumentar la eficacia de las políticas realizadas. El primer factor consiste en el fortalecimiento del nivel de integración del sector de la inclusión social y la reconciliación ${ }^{20}$, por la simple razón que, por ser más efectivas, las acciones de lucha contra la pobreza y el fortalecimiento de la inclusión social deben aprovechar la multiplicidad y la riqueza de los aportes de varias entidades e instituciones y mantener al mismo tiempo una sólida unidad de acción en la formulación e implementación de las políticas públicas vigentes.

Otro tema está representado por el fortalecimiento de la dimensión intersectorial e interinstitucional. Al respecto, iniciativas como la Red Unidos, sobre todo en lo referente a su dimensión de coordinación interinstitucional entre varias entidades públicas y privadas, parecen encaminadas en la dirección correcta. Sin embargo, es oportuno aumentar todavía más los esfuerzos en este ámbito y fortalecer la articulación entre las entidades nacionales y locales. Al respecto, podría ser útil estructurar unos servicios locales de atención y acompañamiento a los beneficiarios que no logran cumplir con las condicionalidades previstas por MFA.

En este contexto, el desarrollo de políticas de cohesión social que aborden el tema de la equidad en el acceso a los recursos y oportunidades representaría un enfoque más efectivo de la búsqueda de un crecimiento polarizado en ciertas zonas del país. En particular, para consolidar el papel del sector público y de las autoridades locales (alcaldías y departamentos), se hace prioritario profundizar el proceso de descentralización y por esta vía, viabilizar una mayor participación de lo local en la definición de las estrategias de desarrollo socioeconómico. Al respecto, vale la pena recordar el caso de Brasil, donde se ha logrado aumentar el impacto del PBF ampliando la descentralización del programa y la responsabilidad del nivel local en su implementación, reforzando al mismo tiempo la colaboración entre los tres niveles de gobierno (federal, estatal y municipal). Esto se ha logrado a través de medidas específicas como: (1) la introducción de un convenio entre el Estado federal y las autoridades locales (Termo de Adesão ao Bolsa Família. Resolución

\footnotetext{
${ }^{20}$ Este sector fue creado en noviembre de 2011. Lo lidera el Departamento Administrativo para la Prosperidad Social (DPS) que es una entidad central y está compuesto por las siguientes entidades descentralizadas: (1) Agencia Nacional para la Superación de la Pobreza Extrema (ANSPE); (2) Unidad Administrativa Especial para la Atención y Reparación Integral a las Víctimas; (3) Unidad Administrativa Especial para la Consolidación Territorial; (4) Centro de Memoria Histórica; e (5) Instituto Colombiano de Bienestar Familiar (ICBF).
} 
GM/MDS 246/05); (2) el diseño y aplicación de un Índice de Gestión Descentralizada $(\mathrm{IGD})^{21}$, que varía de o a 1 y mide la calidad del desempeño de cada municipio; y (3) la vinculación entre el IGD y la cantidad de recursos trasferidos del gobierno federal a cada municipio para la gestión del programa (Ministério do Desenvolvimento Social e Combate à Fome; s.f.).

Otro factor decisivo es la integración de los sistemas informativos sobre los beneficiarios y las actividades realizadas por las entidades que lideran los PTC y los otros programas y estrategias orientados a la lucha contra la pobreza. También en este caso puede ser útil mencionar la experiencia de Brasil que utiliza el Cadastro Único para Programas Sociais (CadÚnico) donde están registradas las familias de bajo ingreso (hasta 50\% del salario mínimo vigente por persona), como base para la focalización de todos los programas de lucha contra la pobreza realizados a nivel federal, estatal o municipal (Programa Bolsa Familia, s.f.; Ibarra, 2014, p. 5; pp. 27-28).

Finalmente, en lo referente al sistema de monitoreo de MFA, sería oportuno no dedicarse únicamente al seguimiento del cumplimiento de las actividades a través de indicadores de proceso y elaborar indicadores de resultado, recopilar los datos necesarios para averiguar, por ejemplo, el logro del objetivo general y de los objetivos específicos del programa.

\section{Conclusiones}

En esta última parte del texto se presentan las principales conclusiones alcanzadas con énfasis en los cinco temas tratados en la tercera parte del artículo. Antes de abordarlos se señalan a continuación dos cuestiones horizontales de gran envergadura. La primera es la necesidad de elaborar políticas a mayor escala que cuenten con un alto nivel de estabilidad institucional y de consenso social y que tengan una adecuada proyección temporal, sin contar únicamente con la duración de un solo mandato presidencial y apuntando a la formulación de políticas de Estado de largo plazo respaldadas con recursos ordinarios del presupuesto nacional. Como recuerda la FAO (2010, p. 8) "los PTC han llegado a poblaciones históricamente excluidas de la protección social. Sin embargo, las personas pueden llegar a graduarse de determinados programas, pero no por ello se desprenden de su derecho a la protección social” (FAO, 2010, p. 8). La segunda es la profundización de los esfuerzos orientados a la equidad entre hombres y mujeres ya que, a pesar de los avances logrados, la desigualdad de género sigue siendo un punto crítico de los PTC, dada la evidencia existente sobre el impacto en la dedicación casi exclusiva de la mujer a las funciones reproductivas y de cuidado de la familia.

${ }^{21}$ La composición, la medición y la aplicación del IGD están reglamentadas por la Ley 12.058 del $13 / 10 / 2009$. 
En lo referente a la articulación entre PTC y sistema de protección social, un riesgo relevante es que los PTC gradúen familias que corren el riesgo de recaer en la pobreza después de la salida del programa. $\mathrm{Al}$ respecto, es importante que las estrategias de egreso no se vean supeditadas únicamente al tiempo de permanencia y a las condiciones de elegibilidad. Por el contrario, es necesario avanzar en la construcción de un sistema de protección social sólido y bien estructurado, y por ende capaz de acompañar las familias durante y después del período de afiliación a MFA y a los otros programas. Un sistema de protección social de esta naturaleza tendría que incluir aspectos como los siguientes: (1) cobertura digna y suficiente en lo referente a los servicios de salud y educación, nutrición; (2) existencia de servicios de acompañamiento enfocados en la adquisición de capacidades y el logro de la plena inclusión social y productiva, incluida la promoción del acceso a un trabajo decente; y (3) logro de una condición de doble inclusión (social y productiva).

En este marco hay que considerar las transferencias monetarias como una medida enmarcada en el reconocimiento progresivo del derecho a contar con ingresos suficientes para llevar una vida digna. Por esto, podría ser oportuno replantear parcialmente la función de las condicionalidades en los PTC. Las mismas tendrían que evitar el estigma de la pobreza y una connotación punitiva, y fomentar la corresponsabilidad entre familias y Estado. Su mayor o menor grado de cumplimiento podrías ser utilizados como indicadores de la dificultad en el camino hacia la superación de la exclusión social, mientras que los servicios de acompañamiento deberían ayudar a las familias a enfrentar y superar exitosamente dichas dificultades.

Otro tema central es la ruralización de la lucha contra la pobreza. Al respecto, más allá de los avances logrados en el rediseño de la estrategia global de MFA, es vital poner el área rural al centro de la agenda política, tanto a nivel nacional como local. Por ende, se hace ineludible la formulación de políticas integradas construidas con la participación de todos los ministerios involucrados, sin limitarse únicamente a los del sector social. Para lograrlo, hay que priorizar la conversión de regiones rurales y territorios de alta vulnerabilidad en áreas atractivas que permitan el desarrollo productivo, el arraigo y la posibilidad de llevar a cabo proyectos de vida. Entre otros, esto implica modernizar al ámbito rural con acciones como las que se indican a continuación: mejorar las infraestructuras existentes; aumentar el acceso y la calidad de los servicios (agua, electricidad, salud, educación, acompañamiento psicosocial y socio-laboral, etc.); fomentar el aporte del sector privado y propiciar cadenas productivas especializadas y articuladas a nivel territorial; impulsar políticas que fomenten el cooperativismo social y comunitario, por un lado y la comercialización de los productos del sector agropecuario por el otro.

Pasando al tema de la inclusión productiva, hay que considerar las hipótesis de asociar las transferencias monetarias a la introducción progresiva de una renta mínima 
y de crear servicios municipales ${ }^{22}$ para el empleo que identifiquen la demanda del mercado laboral y promuevan la inclusión laboral de las personas afiliadas a los PTC, de manera complementaria a la acción llevada a cabo por el Servicio Nacional de Aprendizaje (SENA) a nivel nacional. Bajo esta perspectiva sería necesario tener en cuenta los perfiles específicos de los ciudadanos más vulnerables y la dimensión territorial, e impulsar políticas que fortalezcan los procesos de auto-organización de los trabajadores, así como complementar la capacitación temática para la empleabilidad con el fortalecimiento de la formación orientada a la adquisición de habilidades blandas. Por otro lado, se señala la relevancia de tener en cuenta los grupos sociales con características y necesidades específicas, como los desplazados, los indígenas, los afrodescendientes y las personas con discapacidad.

En los últimos años en América Latina los PTC que incluyen elementos pensionales destinados a los adultos mayores que se encuentran en situación de pobreza han aumentado. Al respecto, se considera oportuno incrementar la focalización y la inclusión de los adultos mayores en MFA. En este contexto, valdría la pena analizar la posibilidad de introducir un componente previsional no contributivo en el programa para cubrir a los sectores con escasa o nula capacidad de ahorro para la vejez en forma coherente con un enfoque de derechos. $\mathrm{Al}$ respecto, más allá de los exámenes médicos periódicos que constituyen la condicionalidad más común para la tercera edad, en las áreas rurales los adultos mayores beneficiarios de un eventual programa de pensión no contributiva podrían ser involucrados en proyectos sociales orientados a la difusión entre niños y jóvenes de la cultura y los saberes tradicionales vinculados con el aprovechamiento sostenible de la tierra y los recursos naturales.

En lo que concierne a la organización y gestión operativa, es necesario aumentar en primer lugar la eficiencia de la coordinación interinstitucional del sistema de protección social para maximizar su impacto, reforzando al mismo tiempo las atribuciones decisorias del DPS. Por ende, es fundamental (a) introducir una arquitectura de gestión más integrada, con amplios poderes de decisión e implementación; (b) pasar progresivamente de la existencia de múltiples programas a la adopción e implementación de una política pública estatal, basada en un marco legal sólido y unívoco; y (c) consolidar las actividades orientadas al fortalecimiento de capacidades de las instituciones y de los funcionarios involucrados en la implementación de las políticas antes mencionadas.

De manera complementaria, es importante fortalecer la dimensión local en la implementación de los PTC y del sistema de protección social nacional. En este contexto, el

\footnotetext{
${ }^{22} \mathrm{Al}$ respecto, una experiencia interesante la representan los Puntos de Intermediación Laboral (PIL) que fueron creados en 2009 por la Alcaldía de Medellín en colaboración con el CISP, una ONG de cooperación internacional, y la regional Antioquia del SENA.
} 
Estado nacional tiene que mantener la función estratégica de formulación de las políticas, mientras que las autoridades locales tienen que aumentar progresivamente su injerencia en la implementación de algunos servicios sociales. Al respecto, podría considerarse la hipótesis de aumentar el nivel de responsabilidad de las autoridades locales (con énfasis en las alcaldías) en la ejecución de MFA y otros PTC y vincular al menos parcialmente, algunas transferencias del gobierno nacional u otro tipo de incentivo económico a los resultados conseguidos por cada alcaldía en el logro de los objetivos respectivos.

Finalmente, se destaca que es necesario contar con sistemas de información más integrados desde el punto de vista sectorial (salud, educación, trabajo, etc.) e institucional (nacional, regional, municipal) no solo para mejorar la focalización, sino también para darle seguimiento a las características, trayectorias y necesidades puntuales de las familias usuarias. Al respecto, podría estudiarse la posibilidad de adoptar la plataforma informática y los datos relativos a los beneficiarios de MFA como base de referencia para la focalización de todos los programas, nacionales y locales, orientados a la lucha contra la pobreza en Colombia.

\section{Referencias}

Bertranou, F. M., Solorio C., \& van Ginneken, W. (2002). Pensiones no contributivas y asistenciales. Argentina, Brasil, Chile, Costa Rica y Uruguay. Santiago de Chile: Oficina Internacional del Trabajo (OIT).

Bogliacino, F., \& Muñoz, M. (2015). Equidad e inequidad en el PND. En UNAL. Plan Nacional de Desarrollo 2014-2018: siempre el mismo país (pp. 7-10). Bogotá: Universidad Nacional de Colombia (UNAL). Colección Controversias.

Bosch, M.; Melguizo, Á., \& Pagés, C. (2013). Mejores pensiones, mejores trabajos. Hacia la cobertura universal en América Latina y el Caribe. Washington: Banco Interamericano de Desarrollo (BID).

Casassas, D., \& Raventós D. (2011). La renta básica en la era de las grandes desigualdades. Barcelona: Montesinos.

Castro, J. A. (2013). Política social, distribuição de renda e crescimento econômico. En Fonseca, A., \& Fagnani, E. (Orgs.). Políticas sociais, desenvolvimento e cidadania. Economia, distribução da renda e mercado de trabalho. Vol. 1, (pp. 167-196). São Paulo: Editora Fundação Perseu Abramo, Coleção Projetos para o Brasil.

Cecchini, S., \& Madariaga, A. (2011). Programas de transferencias condicionadas. Balance de la experiencia reciente en América Latina y el Caribe. Cuadernos de la CEPAL 95. Santiago de Chile: Comisión Económica para América Latina y el Caribe (CEPAL). 
Cecchini, S., \& Martínez, R. (2011). Protección social inclusiva en América Latina. Una mirada integral, un enfoque de derechos. Libros de la CEPAL 111. Santiago de Chile: CEPAL.

CEPAL (2010). La hora de la igualdad. Brechas por cerrar, caminos por abrir. Santiago de Chile: CEPAL.

Claux, M. L., \& La Rosa, M. I. (2013). Competencias valoradas para la empleabilidad. Marco conceptual y experiencias internacionales. Documento inédito. Bogotá: EUROsociAL.

CODHES (2013). La crisis humanitaria en Colombia persiste: el Pacífico en disputa. Informe de desplazamiento forzado en 2012. Documentos CODHES $\mathrm{N}^{\circ} 26$. Bogotá: Consultoría para los Derechos Humanos y el Desplazamiento (CODHES).

Cortés, J. C. (2012). Estructura de la protección social en Colombia. Reforma de la administración pública. Bogotá: Universidad del Rosario, Corporación para el Desarrollo de la Seguridad Social (CODESS) y Legis.

DANE (2013). Pobreza monetaria y multidimensional en Colombia 2012. Boletín de prensa (18/o4/2013). Bogotá: Departamento Administrativo Nacional de Estadística (DANE).

DANE (2015). Pobreza monetaria y multidimensional en Colombia 2014. Boletín de prensa (24/o3/2015). Bogotá: Departamento Administrativo Nacional de Estadística (DANE).

DNP (2013). Marco teórico y herramientas de análisis de intervención psicosocial y desarrollo de habilidades blandas en el marco de la política pública de Generación de Ingresos para población en situación de pobreza extrema y desplazamiento. Bogotá: Departamento Nacional de Planeación (DNP), Grupo de Proyectos Especiales.

DPS (2013). Rediseño del programa Familias en Acción. Documento Operativo Técnico DOT Nº . 07/05/2013. Bogotá: DPS-DNP.

El Espectador (2012, agosto 26). Más de la mitad de indígenas en Colombia está en la pobreza. El Espectador. Recuperado de http://www.elespectador.com/noticias/ nacional/mas-de-mitad-de-indigenas-colombia-esta-pobreza-articulo-370208

EUROsociAL (2014). Acta de Antigua. Conclusiones del Seminario regional sobre articulación entre transferencias monetarias e intervenciones para la inclusión social y productiva: estrategias diferenciadas en las áreas rurales y en las área urbanas. Documento inédito. Antigua: EUROsociAL Programa para la cohesión social en América Latina. 
FAO (2010). Programas de Transferencias Condicionadas en América Latina y el Caribe: perspectivas de los últimos diez años. V Seminario internacional. Septiembre 30 y $1^{\circ}$ de octubre 2010. Santiago de Chile: FAO.

Gamboa, R. E. (2006). Evaluación del sistema del pago del Bonosol. Análisis Ecoñomico UDAPE, 21, 62-82.

Gasparini, L., Crosta, F., Haimovich, F., Álvarez, B., Ham, A., \& Sánchez, R. (2008). Un piso de protección social en América Latina. Costos fiscales e impactos sociales. Documento de Trabajo del CEDLAS N ${ }^{\circ}$ 71. Buenos Aires: EUROsociAL, Organización Internacional del Trabajo (OIT) y Universidad Nacional de La Plata: Centro de Estudios Distributivos, Laborales y Sociales (CEDLAS). Recuperado de http://sedici.unlp.edu.ar/bitstream/handle/10915/3630/Documento_completo__.pdf?sequence $=1$

Graziano da Silva, J., \& Tavares, L. (2010). Sobre o futuro da Bolsa Família. En Castro, J. A., \& Modesto, L. (Orgs.). Bolsa Família 2003-2010: avanços e desafios (Vol. 2, Cap. 11, pp. 235-265). Brasília: Instituto de Pesquisa Económica Aplicada (IPEA).

Huepe, M., \& Larrañaga, O. (2010). El sistema de pensiones solidarias. En Larrañaga O., \& Contreras, D. (Eds.). Las nuevas políticas de protección social en Chile (pp. 157-188). Santiago de Chile: Uqbar Editores.

Ibarra, A. (2014). Estudio regional sobre reglas de graduación y estrategias de egreso de los beneficiarios de los PTC. Caso Brasil. Documento inédito. Brasilia: EUROsociAL.

Leichsenring, A. R. (2010). Precariedade Laboral e o Programa Bolsa Família. En Castro, J. A., \& Modesto, L. (Orgs.). Bolsa Família 2003-2010: avanços e desafios (Vol. 1, Cap. 9, pp. 271-300). Brasília: IPEA.

Midaglia, C. (2012, mayo-junio). Un balance crítico de los programas sociales en América Latina. Caracas: Nueva Sociedad (239), 79-89.

Ministério do Desenvolvimento Social e Combate à Fome (s.f.) Bolsa Família Transferência de renda e apoio à família no acesso à saúde e à educação. Brasilia: Ministério do Desenvolvimento Social e Combate à Fome Secretaria Nacional de Renda de Cidadania (Senarc). Recuperado de http://www.mds.gov.br/ biblioteca/secretaria-nacional-de-renda-de-cidadania-senarc/cartilhas/bolsafamilia-2013-transferencia-de-renda-e-apoio-a-familia-no-acesso-a-saude-ea-educacao/Bolsa\%2oFamilia\%202013\%20Transferencia\%2ode\%2orenda\%20 e\%20apoio\%20a\%2ofamilia\%2ono\%20acesso\%20a\%2osaude\%20e\%20a\%20 educacao.pdf/download 
Programa Bolsa Familia (s.f.) O que é? Cadastro Único para Programas Sociais (CadÚnico). Ministério do Desenvolvimento Social e Combate à Fome. Recuperado de http://www.mds.gov.br/programabolsafamilia/cadastro_unico/o-que-e-1

Rangel, B. M. (2011). Pobreza rural y los programas de transferencias condicionadas en América Latina. Santiago de Chile: RIMISP Centro Latinoamericano para el desarrollo rural.

Raventós, D. (Coord.) (2001). La renta básica. Por una ciudadanía más libre, más igualitaria y más fraterna. Barcelona: Ariel.

Repetto, F. (2010). Protección social en América Latina. La búsqueda de una integralidad con enfoque de derechos. Revista del Centro Latinoamericano de Administración para el Desarrollo (CLAD). Reforma y democracia. (47), 1-24 .

Rubio, G., \& Garfias F. (2010). Análisis comparativo sobre los programas para adultos mayores en México. Santiago de Chile: CEPAL.

Tassara, C. (2014, enero-junio). Cohesión social y PTC en América Latina: una nueva frontera de la cooperación internacional en la lucha contra la pobreza. Revista Internacional de Cooperación y Desarrollo, 1(1), 6-33.

Tassara, C. (Ed.) (2015). Protección social y lucha contra la pobreza en Brasil, Colombia y Chile. ¿Graduarse de los PTC o salir de la pobreza? Madrid: Programa EUROsociAL y Fundación Internacional y para Iberoamérica de Administración y Políticas Públicas (FIIAPP).

van Parijs, P., \& Vanderborght, Y. (2006). La renta básica: una medida eficaz para luchar contra la pobreza. Barcelona: Paidós.

Vargas, L. E. (2014). Estudio regional sobre reglas de graduación y estrategias de egreso de los beneficiarios de los PTC. Caso Chile. Documento inédito. Santiago de Chile: EUROsociAL. 